\title{
XII International Materials Research Congress Held in Cancún in August
}

The Academia Mexicana de Ciencia de Materiales (also known as MexicanMaterials Research Society) organizes the International Materials Research Congress annually as an interactive forum for discussing advances in synthesis, characterization, properties and processing, applications, basic research trends, and education in the area of materials research. The XII International Materials Research Congress (IMRC-2003) was held August 17-21, 2003, in Cancún, México.

IMRC-2003 consisted of 23 symposia attended by 420 delegates from 19 countries. There were 676 presentations delivered as invited talks and oral and poster presentations. This year, the scholarship program, previously suspended for financial reasons, was reinstated, providing 27 scholarships to researchers, which helped draw in 132 students. The congress also had an international demonstration and exhibit section with the participation of 12 companies.

Along with the symposia were plenary sessions, tutorials, and a round table on "Nanoscience and Nanotechnology in Mexico: Present and Future." The main message iterated in the round table is that Mexico needs to determine what role to take in this emerging field of research.

Among the plenary speakers were Ivan K. Schuller (University of California, San
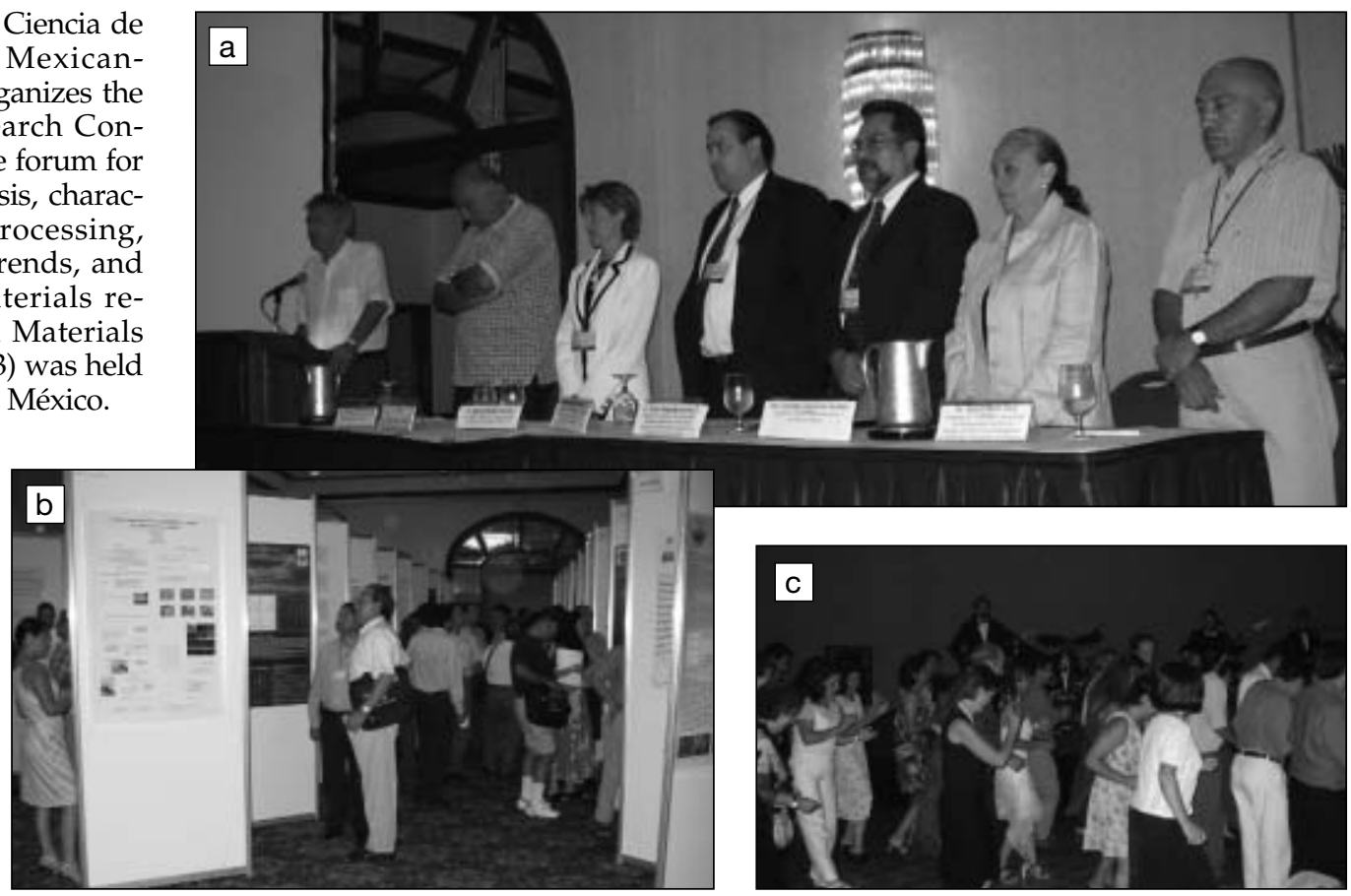

(a) The opening session of the XII International Materials Research Congress; (b) the poster session; (c) entertainment during the conference dinner.

Diego) speaking on " 25 Years of Metallic Superlattices"; Reshef Tenne (Weizmann Institute of Science, Israel) addressing "Inorganic Nanotubes and Inorganic Fullerenelike Structures from Concept to Applications"; and José Reyes Gasga (Universidad Nacional Autónoma de
México) on the "Structure of Human Tooth Enamel."

The next congress (IMRC-2004) will be held August 22-26, 2004, in Cancún, México.

VENTURA RODRíGueZ LUGO President, Mexican-MRS

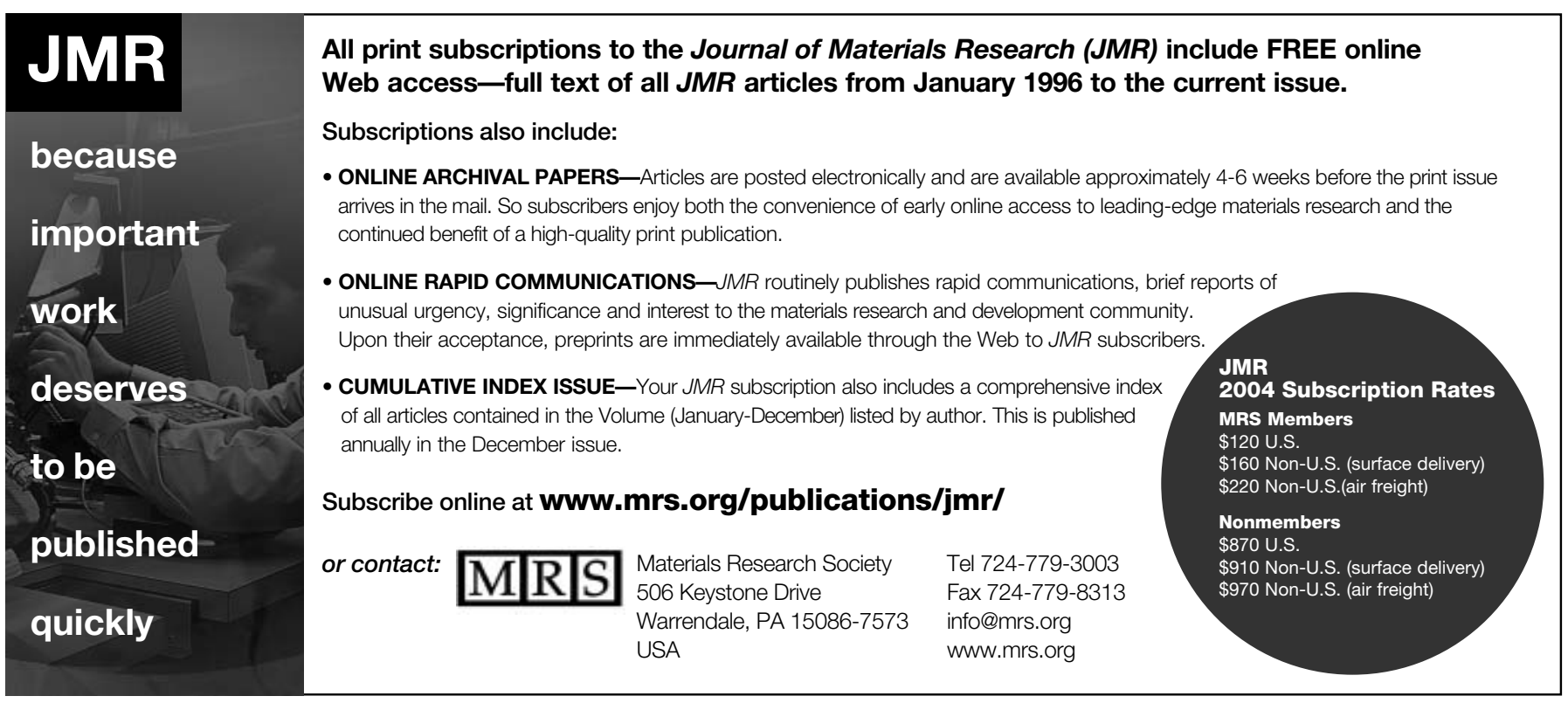

